\title{
Peningkatan Unit Pengawas Urusan Gerbong (PUG) Menjadi Unit Pelaksana Teknis (Depo) Di Rewulu
}

\author{
Hartono AS, Syamsul Abdul Rahman, Siti Umiyati \\ KERETA API INDONESIA PERSERO \\ Email: hartonoas78@gmail.com
}

\begin{abstract}
Abstrak
Demi meningkatkan mobilitas masyarakat yang semakin meningkat setiap tahunnnya pemerintah perlu meningkatkan kapasitas transportasi baik jalan maupun sarana dan prasarananya. Transportasi ialah perpindahan orang atau barang dari suatu tempat ke tempat lainnya atau dari tempat asal ke tempat tujuan dengan menggunakan sebuah sarana yang di gerakan oleh manusia, hewan bahkan mesin. Penelitian ini bertujuan untuk mengetahui dampak dari Peningkatan Unit Pengawas Urusan Gerbong (Pug) Menjadi Unit Pelaksana Teknis (Depo) Di Rewulu. Desain penelitian ini menggunakan pendekatan literatur dengan menggunakan data primer dan data sekunder. Dari hasil Penelitian didapatkan hasil bahwa fungsi Unit Pengawas Urusan Gerbong akan di tingkatkan menjadi Depo Gerbong Kelas C di Rewulu. Terdapat Kekurangan Pegawai Sebanyak 18 Pegawai (Pelaksana/Teknisi) Dan Belum Semua Pegawai Memiliki Sertifikat Kompetensi Tenaga Perawatan Sarana Perkeretaapian. Dalam rangka peningkatan status masih ada beberapa fasilitas yang belum memenuhi standar fasilitas minimum.
\end{abstract}

Kata Kunci: Transportasi, Pengawas Urusan Gerbong (PUG), Kereta Api, Unit Pelaksana Teknis (UPT).

Abstract

In order to increase the mobility of the community, which is increasing every year, the government needs to increase the capacity of transportation, both roads and facilities and infrastructure. Transportation is the movement of people or goods from one place to another or from the place of origin to the destination by using a means that is moved by humans, animals and even machines. This study aims to determine the impact of the Upgrade of the Carriage Supervisory Unit (Pug) to a Technical Implementation Unit (Depo) in Rewulu. This research design uses a literature approach using primary data and secondary data. From the results of the study, it was found that the function of the Carriage Supervisory Unit will be upgraded to a Class $C$ Carriage Depot in Rewulu. There is a shortage of employees as many as 18 employees (executors/technicians) and not all employees have a competency certificate for maintenance personnel for railway facilities. In order to improve the status there are still some facilities that do not meet the minimum standard of facilities.

Keywords: Transportation, Carriage Affairs Supervisor (PUG), Railways, Technical Implementation Unit (UPT). 


\section{A. PENDAHULUAN}

Daerah Istimewa Yogyakarta merupakan daerah istimewa setingkat provinsi di Indonesia yang merupakan peleburan Negara Kesultanan Yogyakarta dan Negara Kadipaten Paku Alaman. Sebagai daerah istimewa tentunya berbagai macam daya tarik wisata menjadi salah satu destinasi favorit bagi pengunjung atau wisatawan. Tidak bisa di pungkiri lagi, berbagai masalah transportasi pasti akan muncul disini, baik dari kondisi jalan yang rusak, dan kemacetan yang terjadi di jalan jalan protokol. Guna menunjang kebutuhan masyarakat, pemerintah harus mengembangkan transportasi yang ada di sini. Transportasi ialah perpindahan orang atau barang dari suatu tempat ke tempat lainnya atau dari tempat asal ke tempat tujuan dengan menggunakan sebuah sarana yang di gerakan oleh manusia, hewan bahkan mesin (Sani, 2010). hal ini bertujuan meningkatkan arus lalu lintas yang cepat, aman, nyaman, tertib, teratur, dan efisien. Karena perkembangan transportasi harus sejalan dengan kebutuhan masyarakat yang terus meningkat. Hal ini tercermin dengan semakin meningkatnya mobilitas penumpang maupun distribusi barang-barang yang terjadi dan peningkatan aktifitas ekonomi sehingga dibutuhkan pula adanya peningkatan terhadap sarana maupun prasarana transportasi itu sendiri.

Daerah Operasi (DAOP) 6 Yogyakarta sebagai salah satu operator penyedia transportasi di Yogyakarta maupun Solo Balapan dalam bidang perkeretaapian dibawah naungan PT. Kereta Api Indonesia. DAOP 6 Yogyakarta memiliki beberapa Stasiun utama, yaitu Stasiun Wates, Stasiun Yogyakarta, Stasiun Lempuyangan, Stasiun Klaten, Stasiun Purwosari, Stasiun Solo Balapan, Stasiun Solo Jebres, Dan Stasiun Sragen. Juga memiliki 4 Depo, antara lain Depo Lokomotif Yogyakarta, Depo Kereta Yogyakarta, Depo Lokomotif Solo Balapan Dan Depo Kereta Solo Balapan, ditambah 1 Pengawas Urusan Gerbong (PUG) dibawah naungan Depo Kereta Yogyakarta. Selain itu juga ada 1 Depo Mekanik untuk perawatan peralatan khusus di Purwosari, dan 1 Balaiyasa Lokomotif Yogyakarta.

Menurut Undang-Undang Nomor 23 Tahun 2007 Tentang Perkeretaapian adalah satu kesatuan sistem yang terdiri atas Prasarana, Sarana, Dan Sumber Daya Manusia, Serta Norma, Kriteria, Persyaratan, Dan Prosedur Untuk Penyelenggaraan Transportasi Kereta Api.Salah satu sarana dari perkeretaapian adalah sarana pengangkut yaitu kereta dan gerbong. Untuk menjaga dan mempertahan kan kondisi kereta agar tetap handal dan laik operasi, maka perlu dilakukan perawatan pada kereta dan gerbong tersebut. Kinerja dan perawatan kereta maupun gerbong akan mencapai hasil yang maksimal apabila sumber daya dan fasilitas penunjang untuk perawatan yang memadai di Depo maupun Balaiyasa yang tersedia.

Berdasarkan Peraturan Menteri Nomor 16 Tahun 2017 Tentang sertifikasi Tenaga Perawatan Sarana Perkeretaapian sebagai peraturan pelaksanaan dari Undang-Undang Nomor 23 Tahun 2007 pasal 29 Tentang Perkeretaapian, bahwa setiap peraturan sarana perkeretaapian wajib memenuhi standar perawatan sarana perkeretaapian dan kualifikasi dibidang sarana perkeretaapian. Adapun perawatan sarana perkeretaapian meliputi perawatan berkala dan perbaikan untuk mengembalikan fungsinya. Tempat melakukan perawatan sarana perkeretaapian sesuai Peraturan Pemerintah No. 6 Tahun 2017 Pasal 235 Ayat 1 yang berbunyi "Perawatan Sarana Perkeretaapian Dilaksanakan Di Depo Atau Balai Yasa Sesuai Dengan Jenis Sarana Perkeretaapian". Pada Ayat 3 berbunyi "Depo Atau Balaiyasa Sebagaimana Dimaksud Pada Ayat 1 Paling Sedikit Dilengkapi Dengan Fasilitas Perawatan Berupa: Jalur Untuk Perawatan, Bangunan Utama Untuk Perawatan, Bangunan Untuk Peralatan Bantu, Dan Bangunan Kantor".

Depo adalah tempat perawatan dan pemeriksaan sarana perkeretaapian untuk Harian, Bulanan, 3 (Tiga) Bulanan, 6 (Enam) Bulanan, Dan 1 (Satu) Tahunan. Untuk sarana perkeretaapian 
di DAOP 6 Yogyakarta sendiri khususnya untuk Lokomotif dan Kereta sudah dibagi terkait perawatannya sesuai Depo yang ditentukan, hanya saja untuk perawatan Gerbong masih dirawat di Pengawas Urusan Gerbong (PUG) yang mana tidak sesuai dengan peruntukannya. maka dibutuhkan peningkatan menjadi sebuah Unit Pelaksana Teknis (Depo) Kelas C agar sesuai dengan Peraturan Pemerintah Nomor 6 Tahun 2017 Pasal 235 Ayat 1 yang berbunyi "Perawatan Sarana Perkeretaapian Dilaksanakan Di Depo Atau Balai Yasa Sesuai Dengan Jenis Sarana Perkeretaapian”. Juga pengkajian dalam kebutuhan SDM perawatan, selain itu juga fasilitas yang tersedia harus memenuhi ketentuan yang berlaku sesuai peruntukannya Sebagai Unit Pelaksanaan Teknis (Depo) Kelas C. Oleh karena itu dalam kertas kerja wajib diberi judul "Peningkatan Unit Pengawas Urusan Gerbong (Pug) Menjadi Unit Pelaksana Teknis (Depo) Di Rewulu”.

\section{B. METODE}

Rencana penelitian dapat dilakukann ketika informasi-informasi yang dasar sudah diketahui. Dimana untuk informasi tersebut didapatkan dari data sekunder, selain itu diperlukan juga data primer untuk mendukung data sekunder tersebut. Untuk data primer dapat dilakukan dengan mencari tahu kondisi objek penelitian yang sebenarnya. Setelah data primer didapatkan, maka dapat dibandingkan dengan data sekunder. Selanjutnya penelitian memakai metode kepustakaan dengan menggunakan literatur dari berbagai sumber serta catatan perkuliahan yang telah dilaksanakan dan dapat mendukung analisis permasalahan yang ada, sebagai landasan teori pedoman penyusunan penelitian ini.

\section{HASIL DAN PEMBAHASAN}

Saat melakukan analisis terhadap peningkatan Unit Pengawas Urusan Gerbong yang akan menjadi sebuah kesatuan fungsi disebut Unit Pelaksana Teknis (Depo) di Rewulu terdapat beberapa faktor penting yang sangat berpengaruh terhadap apa saja yang harus dikembangkan. faktor tersebut meliputi Kebutuhan Sumber Daya Manusia dan Fasilitas maupun Peralatan sebagai acuan dalam proses perawatan yang memadai setelah menjadi Depo. Tujuan perawatan sendiri adalah menjaga kehandalan dan kelaikan operasi serta ketersediaan sarana gerbong untuk menjamin kelancaran pelayanan angkutan kereta api khususnya angkutan barang. Dalam peningkatan tersebut, berikut faktor penting yang dibutuhkan dan harus memadai setelah menjadi Depo Gerbong.

\section{Sumber Daya Manusia}

Jumlah pegawai PT. Kereta Api Indonesia yang bertugas di Pengawas Urusan Gerbong Rewulu secara keseluruhan sebanyak 18 orang pegawai. Dalam penggolongannya terbagi atas 2 unit kerja yaitu unit produksi dan non produksi. Dalam analisis mengenai Sumber Daya Manusia di Unit Pengawas Urusan Gerbong Rewulu terkait peningkatan Pengawas Urusan Gerbong menjadi Depo Gerbong ada beberapa point yang akan dianalisa

a. Beban Kerja Pegawai

Dalam satu minggu terdapat 6 hari kerja, dengan jam kerja perhari adalah selama 7 jam. Tetapi dilapangan sering terjadi penambahan jam kerja dikarenakan beberapa faktor yang mempengaruhinya. Dalam satu bulan pegawai mimiliki 26 hari kerja.Dari hasil analisis didapatkan hasil perhitungan beban kerja jam orang per pegawai dalam sehari adalah 52 jam perhari. Dapat dilihat bahwa beban kerja secara perhitungan telah melebihi standar yang telah ditentukan sehingga membutuhkan penambahan pegawai agar beban jam kerja orang tidak melebihi batas ketentuan dan pegawai dapat melakukan pekerjaannya dengan maksimal. Disamping itu jam kerja rutin dalam satu shift kerja pegawai adalah 7 jam, dari hasil analisis diatas 
didapatkan hasil perhitungan beban kerja jam orang per pegawai dalam sehari adalah 5 jam perhari. Dapat dilihat bahwa beban kerja secara perhitungan telah memenuhi standar yang telah ditentukan. Bahkan masih bisa ditambah beban pekerjaan yang lainnya.

b. Kebutuhan Pegawai

Berdasarkan analisis beban kerja pegawai terutama pegawai dinas non shift mengenai kebutuhan pegawai perawatan didapatkan kekurangan dalam pegawai. Dari hasil analisis Didapatkan kekurangan pegawai perawatan dinas secara keseluruhan adalah 33 pegawai (teknisi), dengan kondisi eksisting saat ini pegawai perawatan dinas non shift maupun dinas shift berjumlah 15 pegawai. Kekurangan pegawai perawatan sesuai perhitungan dengan metode yang tertera di Keputusan Direksi tentang Metode Perhitungan Bebab Kerja (Work Load) Dan Kebutuhan Pekerja Dilingkungan PT. Kereta Api Indonesia (Persero) adalah 18 pegawai. Dengan kekurangan 18 pegawai tersebut, selain menjadi tenaga perawatan akan ada yang ditugaskan menjadi kepela ruas setelah menjadi unit pelaksana teknis (depo) kelas C.

c. Diklat Fungsional Pegawai

Dari jumlah keseluruhan pegawai di Unit Pengawas Urusan Gerbong Rewulu yaitu 18 pegawai, yang telah mengikuti dan melaksanakan pendidikan pelatihan funsional DTO (Dasar Teknis Operasi) sebanyak 18 pegawai dan ada beberapa yang belum mengikuti dan melaksanakan pendidikan pelatihan Traksi Lintas 2 (TLK 2), Traksi Lintas 3 (TLK 3), dan Traksi Lintas 4 (TLK 4). Dari hasil analisis t masih terdapat pegawai yang belum memiliki sertifikat kompetensi tenaga perawatan sarana perkeretaapian sebagaimana ketentuan Peraturan Menteri Perhubungan Nomor 16 Tahun 2017. Hal tersebut akan berpengaruh terhadap perawatan yang dikerjakan oleh pegawai Unit Pengawas Urusan Gerbong Rewulu apalagi setelah ditingkatkan menjadi Unit Pelaksana Teknis (Depo) Kelas C karena pegawai belum mendapatkan pengetahuan yang seharusnya dalam melkukan perawatan. Dan pegawai yang telah mengikuti pendidikan dan latihan tersebut harus saling interaksi dan engajarkan apa yang telah diperoleh. Dengan demikian keahlian tenaga kerja tidak hanya bergantung dengan satu keahlian saja tetapi depat menguasai keahlian lain.

\section{Fasilitas Unit Pengawas Urusan Gerbong}

Dalam melakukan perawatan diperlukan tempat perawatan yang disebut jalur perawatan, jumlah dan panjang jalur perawatan dimiliki sesuatu depo harus mencukupi dengan banyaknya gerbong yang dirawat tiap harinya. karena banyak gerbong-gerbong yang akan melakukan perawatan maupun gerbong yang telah siap operasi dan ditempatkan di depo yang hanya digunakan ketika gerbong tersebut dibutuhkan atau yang disebut gerbong KLB, sehingga terkadang pegawai untuk melakukan langsiran sering terhambat dan suatu kali pernah harus mendorong gerbong secara manual.

Sesuai Peraturan Menteri Nomor 18 Tahun 2019 Tentang Standar Tempat Dan Peralatan Perawatan Sarana Perkeretaapian, yang tidak tersedia sesuai dengan peraturan menteri adalah pada bangunan utama berupa ruang perawatan komponen, ruang pengawasan dan sistem drainase yang kurang baik. Kemudian pada banguan untuk peralatan bantu berupa gudang suku cadang, ruang penyipanan peralatan perawatan, dan tempat pengolahan limbah (IPAL). Serta pada fasilitas umum berupa tempat ibadah, tempat parkir dan area evakuasi.

Berdasarkan hasil penelitian maka dapat diketahui bahwa fasilitas baik dalam faktor Prasarana Pendukung berupa gedung ibadah, gedung pengamanan (ruang security), tools room, tidak adanya spoor (jalur) kolong, tidak adanya leveling track di spoor stabling, juga IPAL untuk pengolahan air limbah di losd depo, tidak adanya hydrant di losd depo dan lighting arester (penangkal petir). Adapun Fasilitas Pendukung berupa overhead crane untuk mengangkat rangka atas gerbong, forklift, hand pallet, mesin gerinda duduk, mesin snai pipa dan lampu sorot portable. 
serta Tools Perawatan, juga Fasilitas Alat Ukur dan Peralatan Komunikasi seperti announcher audio area depo terutama di losd perawatan dan Adapun layout Pengawas Urusan Gerbong yang akan ditingkatkan menjadi Depo Gerbong di Rewulu berdasarkan Keputusan Direksi diatas, memuat beberapa fasilitas (prasarana) pendukung yang baru. Sebagai berikut :

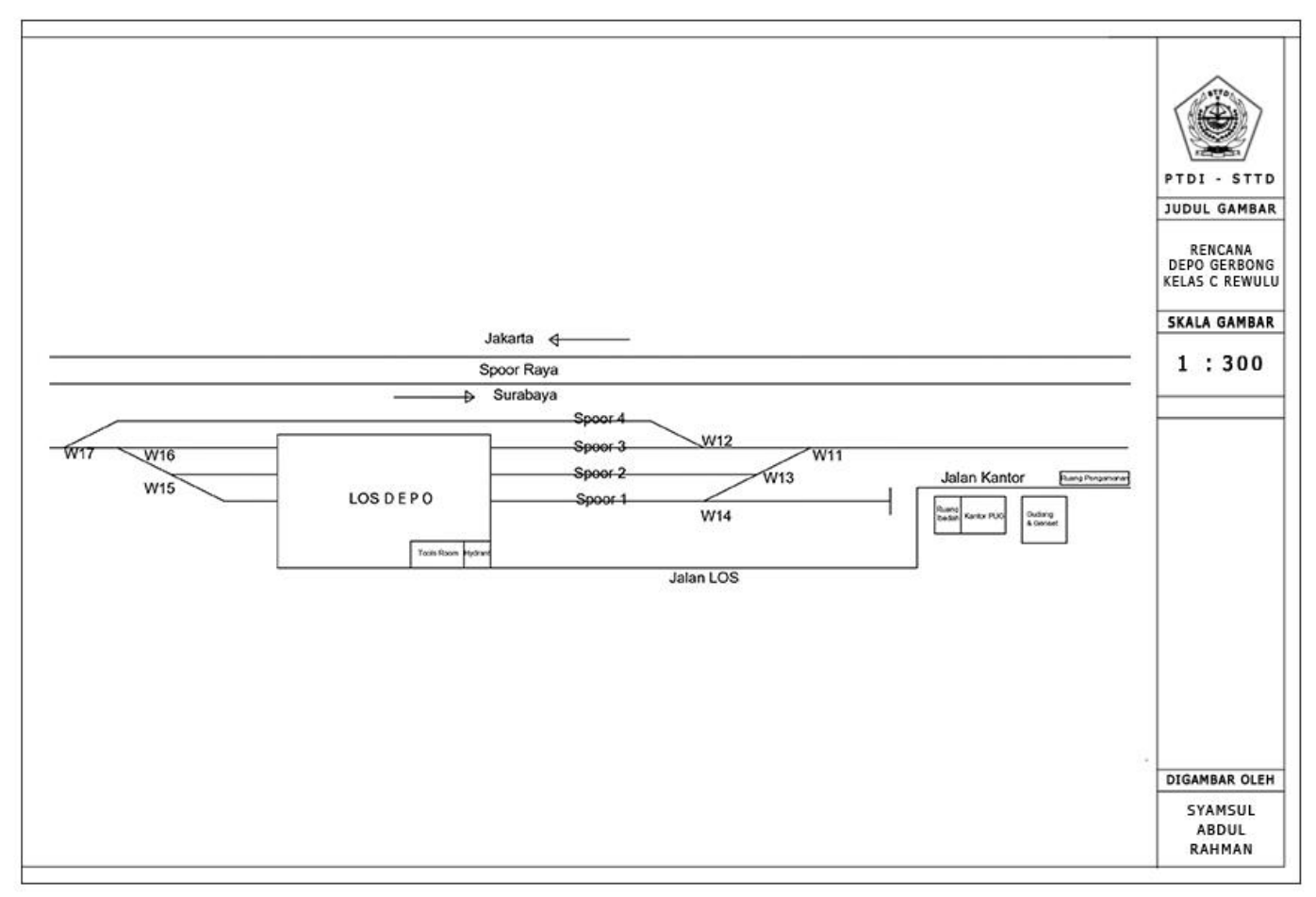

\section{Gambar 1 Layout Baru Depo Gerbong Rewulu}

\section{Peralatan Perawatan Unit Pengawas Urusan Gerbong Rewulu}

Pelalatan merupakan salah satu faktor yang sangat menentukan bekerjanya sistem perawatan di Unit Pengawas Urusan Gerbong Rewulu yang ditingkatkan menjadi sebuah depo gerbong, yang sangat menentukan kualitas dan mutu hasil perawatan serta kelaikan gerbong. Kebutuhan peralatan untuk perawatan depo didasarkan atas proses dan interval waktu perawatan. Dalam menentukan peralatan minimum harus terdapat di Depo Gerbong Kelas C, pendekatan yang digunakan adalah berdasarkan intruksi kerja perawatan gerbong dan juga checkseet perawatan gerbong. Sedangkan sesuai dengan Peraturan Pemerintah Nomor 56 Tahun 2009 tentang Penyelenggaraan Perkereta apian pasal 234 bahwa perawatan saranan perkeretaapian harus menggunakan peralatan sesuai standar, dan sesuai dengan Keputusan Direksi mengenai Standar Fasilitas Minimum. Tidak semua peralatan yang ada bisa digunakan, ada beberapa peralatan yang rusak dan tidak dapat digunakan serta beberapa alat ukur yang belum dikalibrasi dan yang bisa mengguanakannya hanya sebagian pegawai saja.

Tabel 1 Kondisi Peralatan Perawatan

\begin{tabular}{|c|l|c|}
\hline NO & KONDISI PERALATAN & JUMLAH \\
\hline 1 & AKTIF & 70 \\
\hline 2 & NON AKTIF (RUSAK) & 5 \\
\hline
\end{tabular}




\section{\begin{tabular}{|c|c|}
\hline TOTAL & 75 \\
\hline Sumber : Pengawas Urusan Gerbong Rewulu, 2020
\end{tabular}}

Dari data diatas terlihat bahwa terdapat 5 peralatan di Unit Pengawas Urusan Gerbong Rewulu dalam keadaan rusak (non aktif) berupa 3 unit dongkrak, 1 unit gerinda tangan, dan 1 Unit las portabel, keadaan ini tentunya dapat mempengaruhi kualitas hasil perawatan. Pada dasarnya kualitas peralatan perawatan sangat mempengaruhi kualitas hasil perawatan. Dengan adanya peralatan yang mengalami kerusakan dapat menggangu kinerja pegawai dalam melkukan perawatan, dalam hal ini perlu tindakan lebih lanjut mengenai peralatan yang mengalami kerusakan, agar kinerja pegawai lebih maksimal. Dengan kata lain paling tidak realisasi dalam intruksi kerja perawatan dapat meningkat dan apabila memungkinkan untuk diperbaiki sebaiknya dilakukan perbaikan secepatnya, sehingga dapat meningkatkan kelangsungan perawatan gerbong dan perlunya koordinasi yang baik antara pegawai perawatan dengan manajemen terhadap peralatan perawatan, sehingga segera diperbaiki untuk mengoptimalkan perawatan gerbong dengan dilakukan perbaikan terhadap peralatan kerja yang mengalami kerusakan dan melengkapi alat-alat kerja (tools) yang belum memenuhi kebutuhan setelah menjadi Depo Kelas C. Berikut beberapa faktor yang harus diperhatikan untuk perlatan perawatan :

a. Memprioritaskan pada kondisi yang mutlak memerlukan Peralatan perawatan harus diprioritaskan pada kondisi yang mutlak memerlukan, yaitu untuk melakukan perawatan pada komponen- komponen utama yang sangat menentukan performa operasi dari suatu sistem.

b. Memperhitungkan beban kerjaPeralatan perawatan harus memperhitungkan beban kerja depo, seperti jumlah armada gerbong yang harus dirawat.

c. Mempertimbangkan lingkup peralatan/mesin. Perlu mempelajari mengenai kegunaan dan kemampuan dari suatu peralatan dalam menunjang sistem dan kegiatan perawatan termasuk kegunaan peralatan khususdan peralatan umum.

d. TeknologiTeknologi peralatan harus sesuai dengan proses dan sistem perawatan serta teknologi gerbong yang akan dirawat.

e. Kehandalan. Peralatan perawaan harus handal dan mempunyai ketelitian tinggi sesuai dengan standar internasional dan disertifikasi oleh lembaga yang berwenang.

Sarana Daerah Operasi VI Yogyakarta dengan perubahan Unit Pengawas Urusan Gerbong (PUG) Rewulu menjadi Depo Gerbong Kelas C Rewulu pada bagian sarana Daerah Operasi VI Yogyakarta, maka secara struktur organisasi harus berdiri sendiri di samping Depo Lokomotif dan Depo Kereta. Peralatan perawatan Unit Pengawas Urusan Gerbong Rewulu perlu tindakan lebih lanjut mengenai peralatan yang mengalami kerusakan, agar kinerja pegawai lebih maksimal. Dengan kata lain paling tidak realisasi dalam intruksi kerja perawatan dapat meningkat dan apabila memungkinkan untuk diperbaiki sebaiknya dilakukan perbaikan secepatnya, sehingga dapat meningkatkan kelangsungan perawatan gerbong dan perlunya koordinasi yang baik antara pegawai perawatan dengan manajemen terhadap peralatan perawatan.

\section{KESIMPULAN}

Dari penelitian diatas maka dapat ditarik kesimpulan bahwa dengan tidak sesuainya tugas, pokok, dan fungsi Unit Pengawas Urusan Gerbong maka dari itu akan di tingkatkan menjadi Depo Gerbong Kelas C di Rewulu. Beban kerja pegawai selama setahun masih melebihi standar Jam Orang (JO) yang telah ditentukan. Maka, terdapat kekurangan pegawai sebanyak 18 pegawai (pelaksana/teknisi) dan belum semua pegawai memiliki sertifikat kompetensi tenaga perawatan sarana perkeretaapian. Kondisi eksisting Unit pengawas urusan gerbong untuk ditingkatkannya 
menjadi depo gerbong kelas $\mathrm{C}$ masih beberapa fasilitas yg belum memadai dilihat dari ketentuan peraturan menteri dan standar fasilitas minimum ketentuan dari direksi. Terdapat peralatan yang masih rusak sebanyak $7 \%$ dari total pelaratan berjumlah 75 buah dan masih terdapat beberapa peralatan yang belum tersedia seperti crane, dan forklift. Untuk tidak adanya alat tersebut dapat digantikan menggunakan dongkrak.

Penambahan jumlah tenaga perawatan setelah ditingkatkannya Unit Pengawas Urusan Gerbong menjadi depo Gerbong Kelas $\mathrm{C}$ di Rewulu sesuai dengan analisis perhitunagan kebutuhan pegawai yang telah dilakukan yaitu dengan penambahan 18 pegawai (teknisi), dan perlu diadakan evaluasi lebih lanjut dengan penelitian lebih mendalam tentang kebutuhan JO untuk perawatan dan pemeriksaan gerbong baik di losd maupun dailycheck selain itu perlu mengadakan pendidikan dan pelatihan pada bidang perawatan sarana perkeretaapian untuk pegawai yang belum memiliki sertifikasi Traksi Lintas 3 (TLK3) dan Traksi Lintas 4 (TLK4). Dilihat dari hasil analisis Perlu melakukan pengadaan fasilitas pendukung berupa bangunan baru ataupun penambahan yang sekiranya kurang dari standar fasilitas minimum keputusan direksi.

\section{DAFTAR PUSTAKA}

1. Keputusan Direksi PT. Kereta Api Indonesia (Persero) Nomor : KEP.U/KP.101/I/10/KA2014 tentang Metode Perhitungan Beban Kerja Dan Kebutuhan Pekerja.

2. Keputusan Direksi PT. Kereta Api Indonesia (Persero) Nomor: KEP.U/KP.101/I/10/KA-2014 tentang Metode Perhitungan Beban Kerja Dan Kebutuhan Pekerja.

3. Keputusan Menteri Nomor 81 Tahun 2000 Tentang Sarana Kereta Api

4. Peraturan Menteri Nomor 18 Tahun 2019 Tentang Standar Tempat Dan Peralatan Perawatan Sarana Perkeretaapian.

5. Peraturan Menteri Nomor 94 Tahun 2010 Tentang Tenaga Perawatan Sarana Perkeretaapian.

6. Peraturan Pemerintah Nomor 56 Tahun 2009 Tentang Penyelenggara Perkeretaapian

7. RAKHMATULLAH, ARYA DAFFA. (2019) : Rasionalisasi Kebutuhan Fasilitas Dan Sumber Daya Manusia Perawat LRT Di Depo Workshop LRT Sumatera Selatan, Kertas Kerja Wajib (KKW) Program DIII Perkeretaapian, Sekolah Tinggi Transportasi Darat.

8. RISMANA, RIDO EKA (2015) : Analisis Kebutuhan SDM Perawatan Lokomotif Di Depo Tanjungkarang, Kertas Kerja Wajib (KKW) Program DIII Perkeretaapian, Sekolah Tinggi Transportasi Darat.

9. SETYANINGSIH, VIVI. (2018) : Peningkatan Kinerja Perawatan Lokomotif Di Dpo Lokomotif Medan, Kertas Kerja Wajib (KKW) Program DIII Perkeretaapian, Sekolah Tinggi Transportasi Darat.

10. Undang-Undang Nomor 13 Tahun 2003 Tentang Ketenagakerjaan

11. Undang-Undang Nomor 23 Tahun 2007 Tentang Perkeretaapian 